\title{
A NEW APPROACH FOR THERMAL RESISTANCE PREDICTION OF DIFFERENT COMPOSITION PLAIN SOCKS IN WET STATE (PART 2)
}

\author{
Tariq Mansoor*, Lubos Hes and Vladimir Bajzik \\ Faculty of Textile Engineering, Technical University of Liberec, Liberec, Czech Republic \\ *Corresponding author. Email: tariq.mansoor@tul.cz, taheembava1@gmail.com
}

\begin{abstract}
:
Socks' comfort has vast implications in our everyday living. This importance increased when we have undergone an effort of low or high activity. It causes the perspiration of our bodies at different rates. In this study, plain socks with different fiber composition were wetted to a saturated level. Then after successive intervals of conditioning, these socks are characterized by thermal resistance in wet state at different moisture levels. Theoretical thermal resistance is predicted using combined filling coefficients and thermal conductivity of wet polymers instead of dry polymer (fiber) in different models. By this modification, these mathematical models can predict thermal resistance at different moisture levels. Furthermore, predicted thermal resistance has reason able correlation with experimental results in both dry (laboratory conditions moisture) and wet states.
\end{abstract}

\section{Keywords:}

Thermal resistance, plain socks, Mathematical models, wet state

\section{Introduction}

Consumers consider comfort as one of the most important attributes in their purchase of apparel products; therefore, companies tend to focus on the comfort of apparel products. Comfort is a pleasant state of physiological, psychological, and physical harmony between a human being and the environment [1]. Clothing comfort has two main aspects that combine to create a subjective perception of satisfactory performance: thermo-physiological and sensorial. The thermo-physiological relates to the way clothing safeguards and dissipates metabolic heat and moisture $[2,3]$, whereas the sensorial relates to the interaction of clothing with the senses of the wearer $[4,5]$. Thermal-wet comfort being the strongest among tactile and pressure comfort perceived by subjects during exercise [6].

Dry heat transfer occurs through conduction, radiation, convection, and ventilation, whereas wet heat transfer when sweating includes several additional complex processes including evaporation, wicking, sorption and desorption, wet conduction (additional conductive heat transfer due to the clothing being wet), and condensation of moisture $[7,8]$.

Thermal-wet comfort is mainly determined by the heat and moisture transport of fabric, which is related to fiber characteristics as well as yarn, fabric construction, and fabric finish, recognizing that the extent of their relationship to comfort perception in clothing is also influenced by garment design, cut, and fit. The basic thermal comfort properties are just two: thermal resistance (or insulation) and water vapor resistance (or permeability) [8]. Increasing moisture content in fabrics significantly worsens their ability to transport water vapor. For wool fabrics and wool/viscose blended fabric, the value decreases by over $70-80 \%$. However, in the case of the addition of polyester fibers, the effective permeability of water vapor almost disappears, which is caused by substituting the air in pores by water with higher thermal conductivity. This means also that the physiological properties of the fabric, which is becoming increasingly wet as a result of use, are subject to sudden changes, which significantly affects the quality of the apparel [9]. Oğlakcioğlu and Marmarali measured the thermal resistance of cotton knitted fabric in a wet state. Coolmax wetted fabric was used to simulate wetted skin. About $0.5 \mathrm{ml}$ of water (containing detergent) was injected onto its surface and waited for $1 \mathrm{~min}$ for the liquid had been uniformly distributed within a circle of $45-50 \mathrm{~mm}$. It was found that the wetted fabrics indicate lower thermal insulation and cooler feeling [10]. Clothing thermal insulation decreases during perspiration, and the amount of reduction varies from 2 to $8 \%$, as related to water accumulation within clothing ensembles [11]. Another study on footwear reported about 19-25\% (30$37 \%$ in toes) reduction of thermal insulation during sweating [12]. Kuklane et al. measured the effect of different sweat rates on thermal insulation and found a strong negative correlation. Furthermore, they found that $30 \%$ of the total moisture can stay in socks [13]. Thermal manikin results of dry and wet heat loss are presented from different laboratories for a range of two-layer clothing with similar dry insulations but different water vapor permeabilities and absorptive properties. For each climate, total wet heat loss is predominately dependent on the permeability of the outer layer. At $10^{\circ} \mathrm{C}$, the apparent evaporative heat loss is remarkably higher than expected from 
evaporation alone (measured at $34^{\circ} \mathrm{C}$ ), which is attributed to condensation within the clothing and increased conductivity of the wet clothing layers [14]. The characterization of insulation in wet states is very critical. There are many experimental and prediction models available to fulfill this need. Some researchers employed artificial neural networks (ANNs) models for thermal resistance predictions [15,16]. Hes and Loghin assumed thermal resistance of textile linked parallel to the thermal resistance of water in their suggested mathematical model [17]. Dias and Delkumburewatte's mathematical model predicted higher thermal conductivity than experimental [18]. In the thermal resistance model of Matusiak, all the multilayered fabric assemblies can be defined as cuboids filled with randomly oriented infinite cylinders (fibers). Conductive heat transfer can be calculated by analogy to electrical resistance and Fricke's law [19]. In most of the studies, thermal resistance is predicted by statistical models $[16,17]$. Mangat et al. presented a mathematical model for thermal resistance in the wet state with the series and parallel combinations of air, fiber, and water resistance. Their predictions are in good correlation with experiments by model-3 (air and fiber resistance in series, water in parallel) for denim fabrics while model-5 $\left(R_{\mathrm{a}}\right.$ and $R_{\mathrm{w}}$ in parallel arrangement and $R_{\mathrm{f}}$ in series) and model-7 $\left(R_{\mathrm{f}}\right.$ and $R_{\mathrm{w}}$ in serial arrangement and $R_{\mathrm{a}}$ in parallel arrangement) for weft knitted fleece fabric of differential fiber composition [18,19]. Hollies and Bogaty have suggested a parallel combination for measuring the effective thermal conductivity of moisten fabric by combining the volume fraction and thermal conductivity of water and polymer [20]. Naka and Kamata suggested three parameters (air, water, and polymer) model with the combination of parallel and series arrangements [21]. The problem with Mangat's models that they assumed the filling coefficient or conversely porosity as constant components. But they are changed with the changing of moisture levels because water has a different density. Their second assumption that the air is replaced by water is also not correct because of even $>200 \%$ moisture content air still present in the fabric. A mathematical model for thermal resistance prediction, suggested by Wei et al. [22], is also very simple like Mangat's model. But they considered only fiber and air resistances. They ignored the water content. Their recommended model has fiber and air in series plus air in parallel. Hollies and Bogaty have ignored the series arrangement and their calculation for water volume presented in the fabric is also not clear. Naka and Kamata suggested three parameters (air, water, and polymer) model that was a good attempt but not conclusive, that is, use series, parallel, or combination of both.

Although there are enough prediction models available for different fabrics, these models are very complicated and limited to dry states. So the present research aims to measure the thermal resistance by different skin models and find or develop a simple mathematical model for thermal resistance prediction based on available physical parameters especially in wet states for socks with differential fiber composition.

\section{Material and methods}

\subsection{Materials}

All the socks samples have been knitted on the same machine (Lonati 144N 4") settings by varying the main yarns to get the homogeneous samples with respect to specs and stretches for contrast comparison. After knitting, all the samples were processed for washing in the same machine bath followed by tumble drying and boarding.

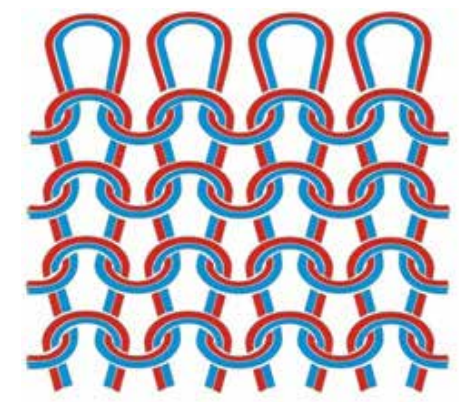

Figure 1. Plain sock construction.

Table 1. Sock samples specifications

\begin{tabular}{|c|c|c|c|c|}
\hline Fiber composition (\%) & $\begin{array}{c}\text { GSM } \\
\left(\mathrm{g} / \mathrm{m}^{-2}\right)\end{array}$ & $\begin{array}{l}\text { Thickness } \\
\text { (mm) }\end{array}$ & $\begin{array}{c}\text { Fabric volumetric } \\
\text { density }\left(\mathrm{kg} / \mathrm{m}^{-3}\right)\end{array}$ & $\begin{array}{l}\text { Sock } \\
\text { codes }\end{array}$ \\
\hline Cotton $80 \%$, polyester $18.20 \%$, and elastene $1.8 \%$ & 276.45 & 1.080 & 255.95 & $\mathrm{P} 1$ \\
\hline Viscose $81.08 \%$, polyester $17.22 \%$, and elastene $1.70 \%$ & 373.98 & 1.06 & 352.82 & $\mathrm{P} 2$ \\
\hline Polyester $98.38 \%$ and elastene $1.62 \%$ & 252.03 & 0.96 & 262.53 & P3 \\
\hline Nylon $70.83 \%$, polyester $26.54 \%$, and elastene $2.63 \%$ & 227.64 & 1.09 & 208.85 & P4 \\
\hline Polypropylene $65.22 \%$, polyester $31.65 \%$, and elastene $3.13 \%$ & 211.38 & 1.04 & 204.23 & P5 \\
\hline Wool $76.19 \%$, polyester $21.67 \%$, and elastene $2.14 \%$ & 268.29 & 1.32 & 203.25 & P6 \\
\hline Acrylic $81.25 \%$, polyester $17.06 \%$, and elastene $1.69 \%$ & 390.24 & 1.55 & 251.77 & $\mathrm{P} 7$ \\
\hline
\end{tabular}




\subsection{Methods}

\subsubsection{Alambeta}

Thermal resistance $\left(R_{c t}\right)$ assessed using the Alambeta tester [23], which enables fast measurement of both steady-state and transient-state thermal properties. This instrument simulates, to some extent, the heat flow $q\left(\mathrm{Wm}^{-2}\right)$ from the human skin to the fabric during a short initial contact in the absence of body movement and external wind flow. Thermal resistance $\left(R_{c t}\right)$ $\left(\mathrm{m}^{2} \mathrm{KW}^{-1}\right)$ is used to express the heat insulation properties of a fabric. $R_{c t}$ of textiles is affected by fiber conductivity, fabric porosity, and fabric structure. It is also a function of fabric thickness, as shown by the following expression:

$$
R_{c t}=\frac{h}{\lambda}
$$

\subsection{Theoretical models}

All the theoretical models for thermal resistance prediction are used by feeding the wet fibre thermal conductivity ( $\left.\lambda_{\text {wet polymer }}\right)$ and filling coefficient ( $\left.F_{\text {wet polymer }}\right)$ of wet polymer instead dry and amended accordingly except Mangat's model. $F_{\text {wet polymer }}$ and $\lambda_{\text {wet polymer }}$ are calculated as per Eqs (11)-(13). After this amendment, these models can also predict thermal resistance for wet fabrics.

\subsubsection{Fricke's modified model [24]}

Thermal conductivity of fibrous material whose fibers are perpendicular to the heat flow can be determined by the following equation:

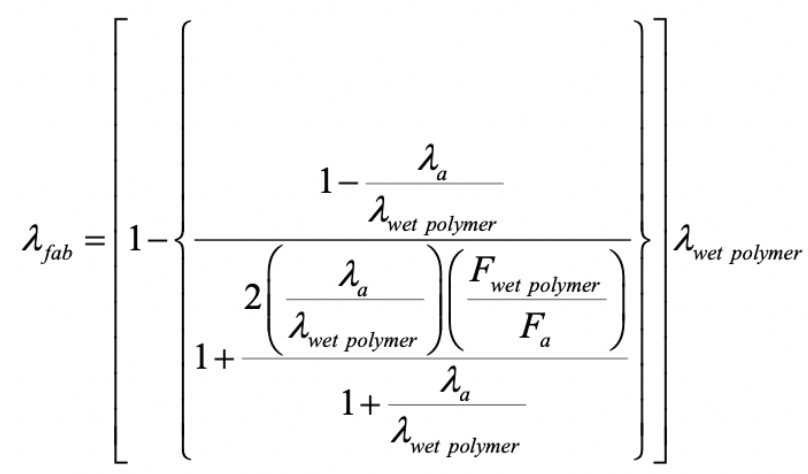

$\lambda_{\text {fab }}=$ Fabric thermal conductivity, $\lambda_{\text {wet polymer }}=$ Wet fibre thermal conductivity, $\lambda_{a}=$ Air thermal conductivity, $F_{\text {wet polymer }}=$ Fiber filling coefficient + Water filling coefficient, and $F_{a}=$ Air filling coefficient.

\subsubsection{Ju Wie modified model}

Wie et al. [22] have divided the fabric basic unit into three parts in heat transfer field: part I is composed of solid fibers, part II is the porosity vertical to the heat flow direction, and part
III is the porosity parallel to the heat flow direction, as shown as Figure 2. Fabric thermal resistance depends largely on the heat transfer process in the basic unit. In this model, heat flow considered through the fabric in a combination of fiber and air in series plus air in parallel.
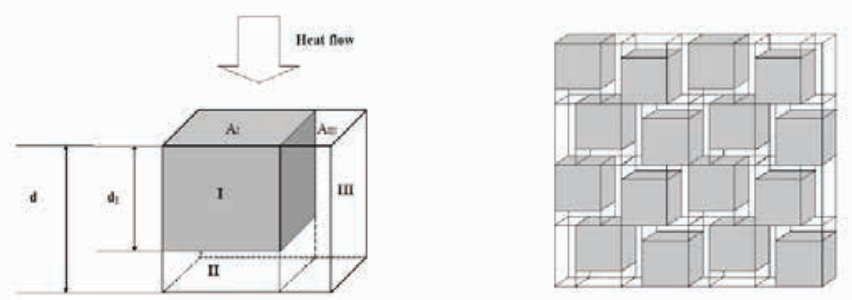

Figure 2. Ju Wie model diagram.

$R_{\text {fabric }}=\frac{D}{\lambda_{\text {air }}}\left[\frac{\lambda_{\text {wet polymer }}-a\left(\lambda_{\text {wet polymer }}-\lambda_{\text {air }}\right)}{\lambda_{\text {wet polymer }}-\left(\lambda_{\text {wet polymer }}-\lambda_{\text {air }}\right)\left(a-F_{\text {wet polymer }}\right)}\right]$

$R_{\text {fabric }}=$ Fabric thermal resistance $\left(\mathrm{m}^{2} \mathrm{KW}^{-1}\right), D=$ Fabric thickness $(\mathrm{m}), \lambda_{\text {air }}=$ Air thermal conductivity $\left(\mathrm{Wm}^{-1} \mathrm{~K}^{-1}\right)$, $\lambda_{\text {wet polymer }}=$ wet fibre thermal conductivity $\left(\mathrm{Wm}^{-1} \mathrm{~K}^{-1}\right), a=$ Fabric structural parameter $=\frac{D_{\text {compresed }}}{D}, D=$ Thickness $(\mathrm{m})$ measured at $2 \mathrm{kPa}$ pressure, while ${ }^{D}$ compressed $=$ Thickness $(\mathrm{m})$ measured at $15 \mathrm{kPa}$.

\subsubsection{Maxwell-Eucken2 (ME2)'s modified model}

Maxwell-Eucken (ME) model [25,26] (Eq. 4) can be used to describe the effective thermal conductivity of a twocomponent material with simble physical structures. In Eq. (4), $\lambda_{a}, \lambda_{\text {wet polymer }}, F_{a}$, and $F_{\text {wet polymer }}$ are the thermal conductivities and volume fractions, respectively, and subscripts representing the two components of the system. $\lambda_{f a b}$ is the effective thermal conductivity of the two-component material. An emulsion is a dispersion of one liquid in another immiscible liquid. The phase that is present in the form of droplets is the dispersed phase and the phase in which droplets are suspended is called the continuous phase. Several effective thermal conductivity models require the naming of a continuous and dispersed phase. The materials with exterior porosity, individual solid particles are surrounded by a gaseous matrix, and hence the gaseous component forms the continuous phase and the solid component forms the dispersed phase [27]. For external porosity, $\lambda_{a}$ and $\lambda_{\text {wet polymer }}$ are considered as continuous and dispersed phases, respectively.

$$
\lambda_{\text {fab }}=\frac{\lambda_{a} F_{a}+\lambda_{\text {wet polymer }} F_{\text {wet polymer }} \frac{3 \lambda_{a}}{2 \lambda_{a}+\lambda_{\text {wet polymer }}}}{F_{a}+F_{\text {wet polymer }} \frac{3 \lambda_{a}}{2 \lambda_{a}+\lambda_{\text {wet polymer }}}}
$$

$F_{\text {wet polymer }}$ and $\lambda_{\text {wet polymer }}$ are calculated as per Eqs (11)(13). 


\subsubsection{Schuhmeister's modified model}

Schuhmeister [28] summarized the relationship between the thermal conductivity of fabric and the fabric structural parameters by the following equations:

$$
\begin{aligned}
& \lambda_{\text {fab }}=0.67 \times \lambda_{s}+0.33 \times \lambda_{p} \\
& \lambda_{s}=\frac{\lambda_{\text {wet polymer }} \times \lambda_{a}}{\lambda_{\text {wet polymer }} F_{a}+\lambda_{a} F_{\text {wet polymer }}} \\
& \lambda_{p}=F_{\text {wet polymer }} \lambda_{\text {wet polymer }}+F_{a} \lambda_{a}
\end{aligned}
$$

where $\lambda_{f a b}$ is the thermal conductivity of fabric, $\lambda_{\text {wet polymer }}$ is the conductivity of wet fibers, $\lambda_{a}$ is the conductivity of air, $F_{\text {wet polymer }}$ is the filling coefficient of the solid fiber, and $F_{a}$ is the filling coefficient of air in the insulation.

\subsubsection{Militky's modified model}

Militký and Becker [29] summarized the relationship between the thermal conductivity of fabric and the fabric structural parameters by an empirical equation:

$$
\begin{aligned}
& \lambda_{f a b}=\left(\frac{\lambda_{s}+\lambda_{p}}{2}\right) \\
& \lambda_{s}=\frac{\lambda_{\text {wet polymer }} \times \lambda_{a}}{\lambda_{\text {wet polymer }} F_{a}+\lambda_{a} F_{\text {wet polymer }}} \\
& \lambda_{p}=F_{\text {wet polymer }} \lambda_{\text {wet polymer }}+F_{a} \lambda_{a}
\end{aligned}
$$

where $\lambda_{f a b}$ is the thermal conductivity of a fabric, $\lambda_{\text {wet polymer }}$ is the conductivity of wet fibers, $\lambda_{a}$ is the conductivity of air, $F_{\text {wet polymer }}$ is the filling coefficient of the solid fiber, and $F_{a}$ is the filling coefficient of air in the insulation.

\subsubsection{Suggested amendments and calculations}

By assuming that fabric density is changing with wetting, which causes to change the filling coefficient, porosity, and thermal conductivity of the fabrics. Based on these assumptions, the following three equations are developed that will be used to find the fabric density, filling coefficient, and thermal conductivity for different moisture levels. Average thermal conductivity for different fibers (within socks) at different moisture levels will be calculated as per Eq. (11):

Average Thermal Conductivity $\left(\lambda_{\text {wet Polymer }}\right)=$

$=\left(\frac{F_{w} \cdot \lambda_{w}+F_{f i b 1} \cdot \lambda_{f i b 1}+F_{f i b 2} \cdot \lambda_{f i b 2}+F_{f i b 3} \cdot \lambda_{f i b 3}}{F_{w}+F_{f i b 1}+F_{f i b 2}+F_{f i b 3}}\right)$

$F_{w}=$ Water filling coefficient, $F_{\text {fib1 }}=$ First fiber filling coefficient, $F_{\text {fib2 }}=$ Second fiber filling coefficient, $F_{\text {fib3 }}=$ Third fiber filling coefficient, $\lambda_{w}=$ Water thermal conductivity, $\lambda_{\text {fib } 1}=$ First fiber thermal conductivity, $\lambda_{\text {fib2 }}=$ Second fiber thermal conductivity, and $\lambda_{\text {fib2 }}=$ Third fiber thermal conductivity.

The filling coefficients for water, fiber, wet polymer, and air are calculated as per below steps:

Air filling coefficient $\left(F_{a}\right)$ is calculated as per the following Eq. (12):

Air filling coefficient $\left(F_{a}\right)=1-\left(F_{w}+F_{f i b}\right)$

Filling coefficient for wet polymer will be calculated as per Eq. (13). This value will be used as input in all the above models for the measurement of thermal resistance in wet states.

Wet polymer filling coefficient $\left(F_{\text {wet polymer }}\right)=F_{w}+F_{f i b}$

Table 2. Filling coefficients calculation

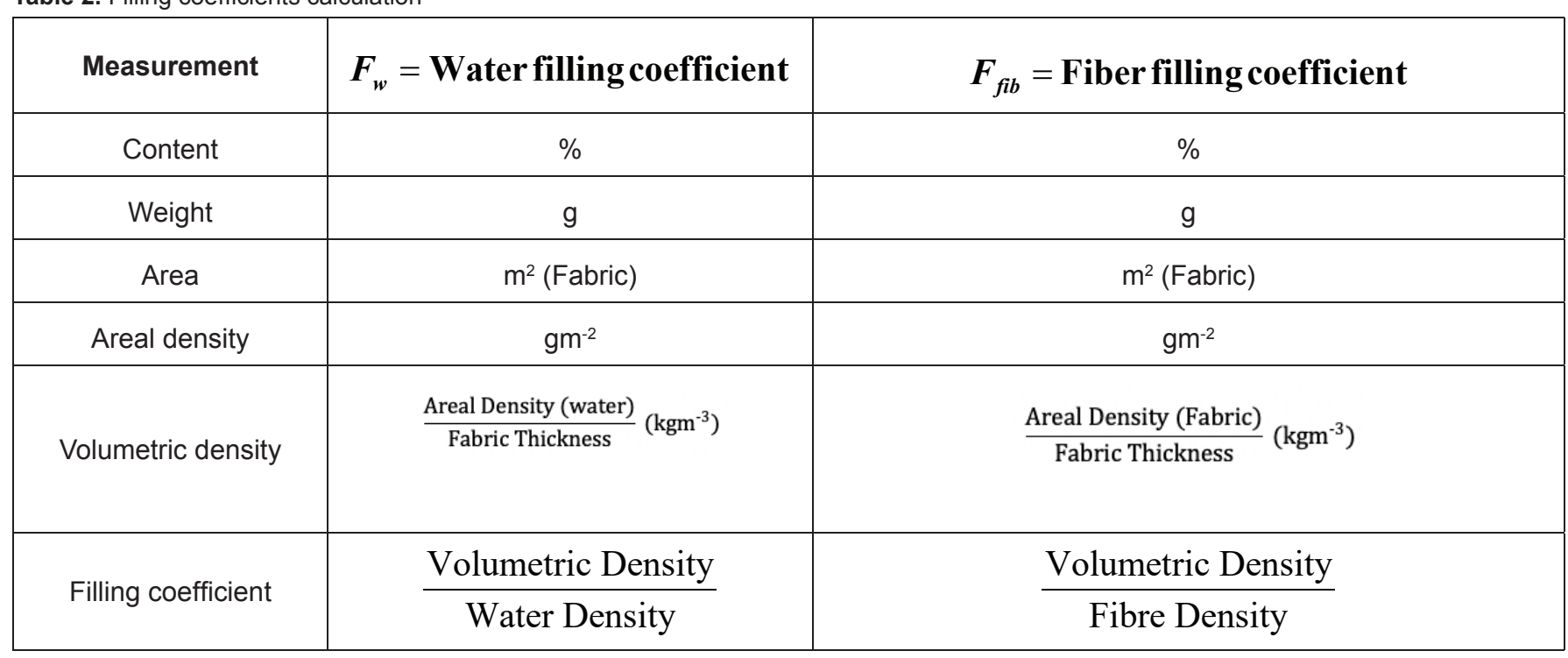


Table 3. Different fibers' properties

\begin{tabular}{|c|c|c|}
\hline Fiber name & Density $\left(\mathbf{k g m}^{-3}\right)$ & $\begin{array}{c}\text { Thermal } \\
\text { conductivity } \\
\left(\mathbf{W m}^{-1} \mathbf{K}^{-1}\right)\end{array}$ \\
\hline Cotton & 1540 & 0.5 \\
\hline Viscose & 1530 & 0.5 \\
\hline Polyester & 1360 & 0.4 \\
\hline Nylon 66 & 1140 & 0.3 \\
\hline Polypropylene & 900 & 0.2 \\
\hline Wool & 1310 & 0.5 \\
\hline Acrylic & 1150 & 0.3 \\
\hline
\end{tabular}

The output of Eqs (11)-(13) is used as input in all the above models. So with the combinations of suggested and abovementioned models, thermal resistance at different moisture levels will be predicted. The thermal conductivity of water and air is taken as 0.6 and $0.026 \mathrm{Wm}^{-1} \mathrm{~K}^{-1}$, respectively, while the density of water is $1000 \mathrm{kgm}^{-3}$. The values of the different input parameters used in this study are given in Table 3 [30].

\subsection{Statistical analysis}

Theoretical and experimental results are statistically analyzed by the coefficient of determination $\left(R^{2}\right)$ and the sum of squares of deviation (SSD). Correlation graphs are drawn through scatter diagrams in Microsoft excel. The following are the equations behind the calculation of $\left(R^{2}\right)$ and SSD [31].

$R^{2}=\frac{s_{x y}^{2}}{S_{x}^{2} S_{y}^{2}}$

$\mathrm{SSD}=\sum_{i=1}^{n}(\text { experimental }- \text { predicted })^{2}$

\section{Results and discussion}

Sock samples were tested for a relative cooling effect, thermal resistance, and thermal absorptivity in the dry state (laboratory conditions moisture content). Then, wet to saturated level (70\% moisture content) by BS EN ISO 105-X12 standard test method. Establish technique for preparing wet fabric of a known ovendry weight of the fabric, then thoroughly wet out it in distilled water. Bring the wet pick-up to $70 \pm 5 \%$ by putting wet testing fabric on a blotting paper. Avoid evaporative reduction of the moisture content below the specified level before the tests are run. Furthermore, tested again after 2, 4, 6, and $8 \mathrm{~h}$ of conditioning successively in laboratory standard environmental conditions at known moisture level.

\subsection{Effect of moisture on thermal resistance $\left(m^{2} K W-1\right)$}

As mentioned earlier, dry and wet socks with differential moisture content were checked on Alambeta. The Alambeta is selected to avoid the effect of convection. Figures 3-11 demonstrated that as the moisture (\%) increased thermal resistance decreased and vice versa irrespective of sock fiber composition or structure. Only P3, P4, and P5 socks have resumed their dry (lab conditions) $R_{c t}$ after $6 \mathrm{~h}$ of conditioning. $\mathrm{P} 2, \mathrm{P} 6$, and $\mathrm{P} 7$ could not resume their thermal resistance even after 8 h. P5 (polypropylene) has the highest moisture loss or evaporation rate followed by P6 (wool) and P3 (polyester). P1 (cotton) and P2 (viscose) are the worst ones. P4 (nylon) and P7 (acrylic) fallen in the middle. Predicted (by different models) and experimental thermal resistance is given in Table 4. For all the models, the input thermal conductivity and filling coefficients were measured for wet polymer at different moisture levels. The correlation between experimental and predicted models is checked by $r^{2}$ value. The values of coefficient of determination for all the models showed that these models can make reasonable predictions of thermal resistance in dry as well as

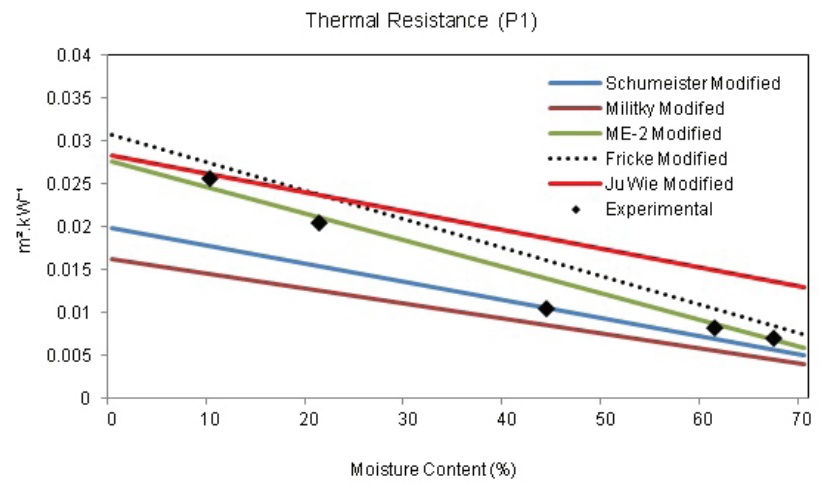

Figure 3. Theoretical thermal resistance vs experimental at different moisture levels (P1)

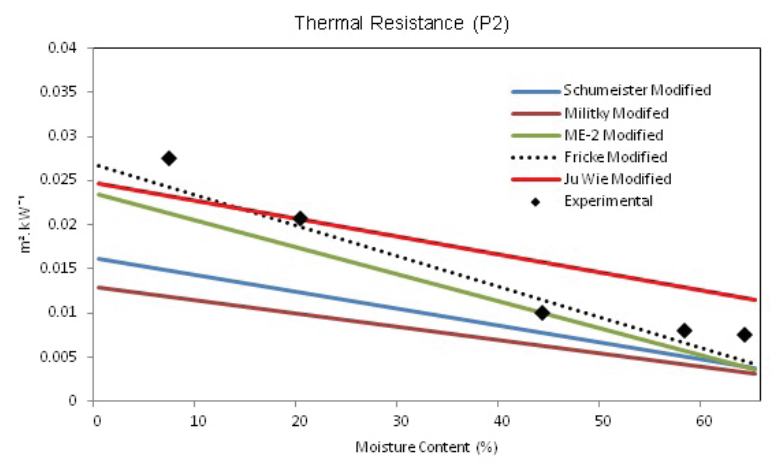

Figure 4. Theoretical thermal resistance vs experimental at different moisture levels (P2)

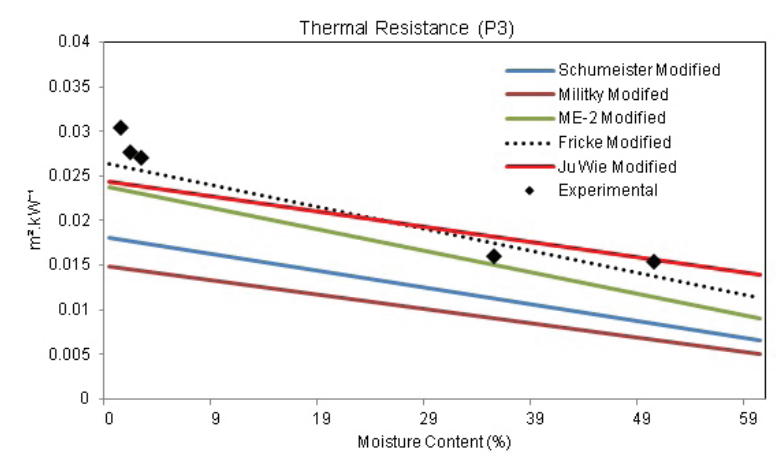

Figure 5. Theoretical thermal resistance vs experimental at different moisture levels (P3). 


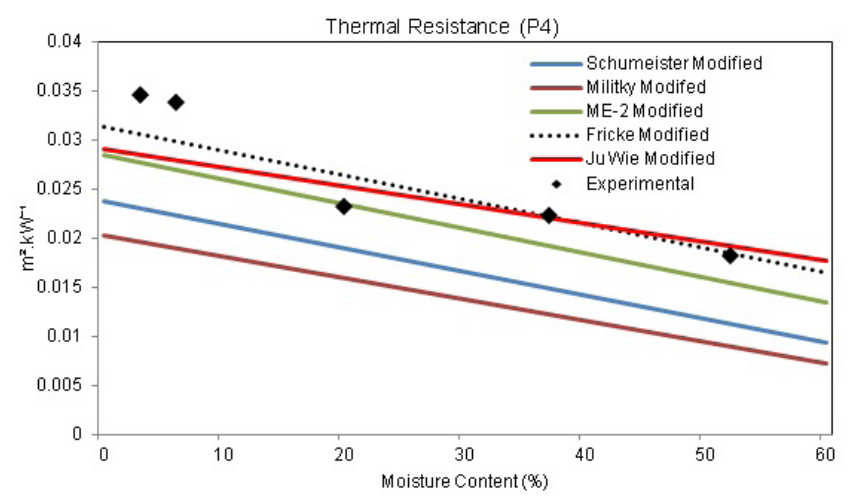

Figure 6. Theoretical thermal resistance vs experimental at different moisture levels (P4).

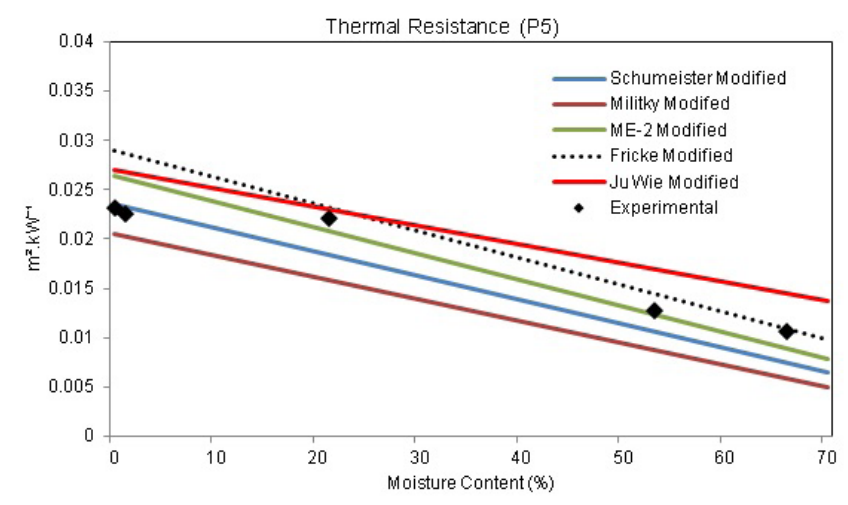

Figure 7. Theoretical thermal resistance vs experimental at different moisture levels (P5).

the wet state also at different moisture levels for all the major fiber blends being used for socks.

The predicted and experimental thermal resistance of $\mathrm{P} 1$ (cotton $80 \%$, polyester $18.20 \%$, and elastene $1.8 \%$ ) at various moisture levels is given in Figure 3. Maxwell model has the best prediction at $10.1 \%, 20.61 \%, 61.17 \%$, and $67.02 \%$ moisture levels followed by Frick, Schuhmeister Militký, and Ju Wie. P1 sample has still about $21 \%$ moisture content after $8 \mathrm{~h}$ of conditioning due to the higher composition of cotton fiber content (80\%).

In the case of $\mathrm{P} 2$ sock (viscose $81.08 \%$, polyester $17.22 \%$, and elastene $1.77 \%$ ), the almost same trend is observed as well as moisture loss is concerned after consecutive periods of conditioning as shown in Figure 4. Maxwell and Fricke have the best thermal resistance prediction at all moisture contents. Schuhmeister and Militký have a good prediction at $43.83 \%$, $57.88 \%$, and $64.46 \%$ moisture contents. Militký has the best prediction at $44 \%, 58 \%$, and $64 \%$ moisture content. Ju Wie has a better prediction where the moisture level is less than $20 \%$.

P3 sock (polyester $98.38 \%$ and elastene 1.62\%) has the highest moisture loss (evaporation rate) due to polyester hydrophobic nature after successive periods of conditioning as shown in Figure 5. Militký's model's prediction is a bad one among all the models. Overall, Fricke has the best prediction

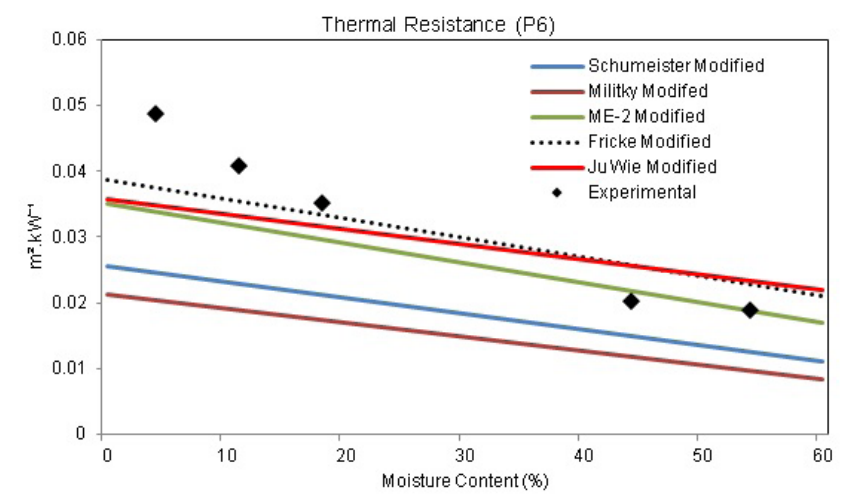

Figure 8. Theoretical thermal resistance vs experimental at different moisture levels (P6).

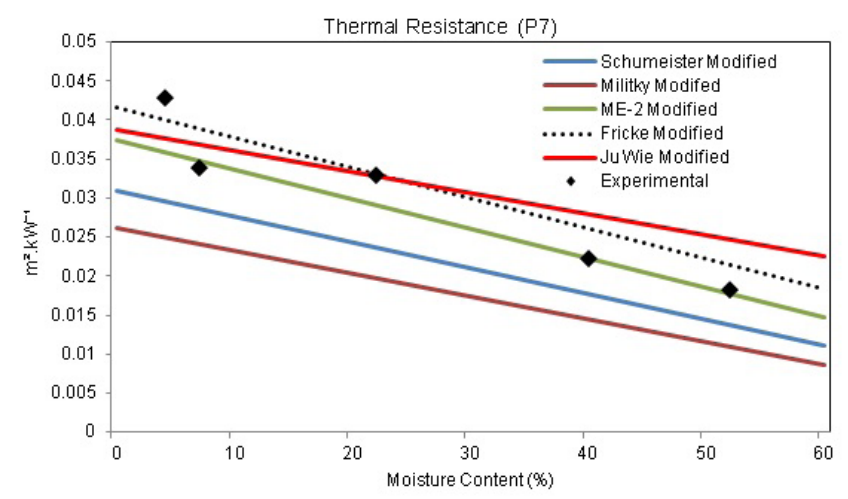

Figure 9. Theoretical thermal resistance vs experimental at different moisture levels (P7).

in dry and wet states at all the moisture levels followed by Ju Wie and Maxwell.

Fricke has overall top thermal resistance prediction generally at $3 \%, 6 \%, 36 \%$, and $52 \%$ moisture level specifically for P4 (nylon $70 \%$, polyester $26.54 \%$, and elastene $2.63 \%$ ) as shown in Figure 6 followed by Ju Wie and Maxwell. Militký again got the lowest position. Schuhmeister on the second number from the lower side. This is also verified from SSD values, that is, $0.0000382,0.0000797,0.0000901$, and 0.000404 for Fricke, Ju Wie, Maxwell, Schuhmeister, and Militký, respectively.

In Figure 7 for P5 (polypropylene 65.22\%, polyester 31.65\%, and elastene $3.13 \%$ ) sock, Schuhmeister and Maxwell's prediction is the best among all other models with less SSD, that is, 0.0000286325 and 0.000031 with respect to experimental thermal resistance. Then, Ju Wie (SSD $=0.0000887$ ) followed by Militký $(S S D=0.000101)$ and Fricke $(S S D=0.000115)$.

Figure 8 shows the effect of moisture content (\%) on the thermal resistance of P6 sock (wool 76.19\%, polyester $21.67 \%$, and elastene $2.14 \%$ ). P6 sock could not resume its dry state moisture content and ultimately thermal resistance after $8 \mathrm{~h}$ of conditioning due to its hydrophilic nature. $7.43 \%$ moisture content is due to the presence of polyester fiber in the composition in the dry state. All the models have a reasonable prediction of thermal resistance as evident in Figure 8. 

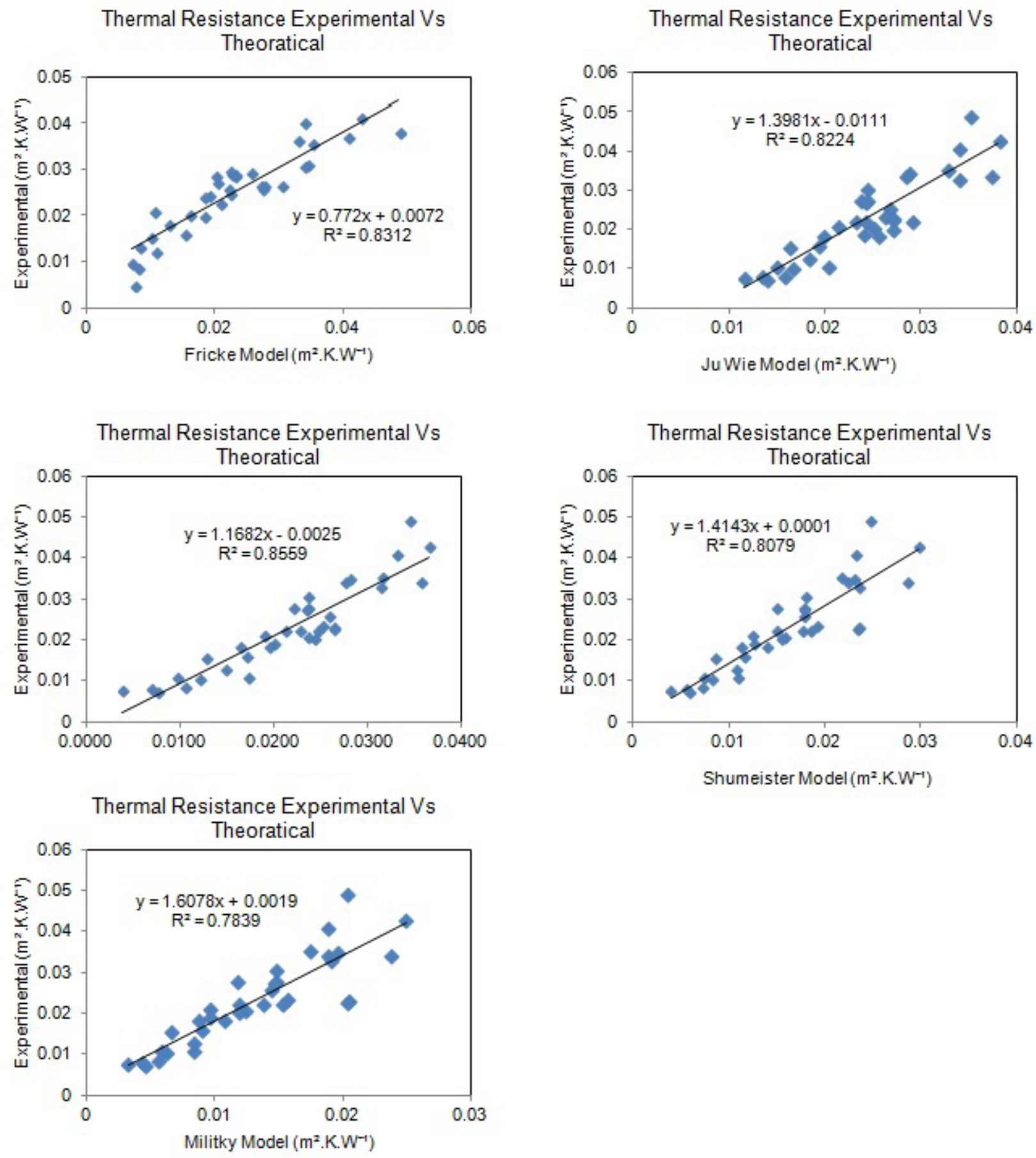

Figure 10. Coefficient of determination predicted vs experimental thermal resistance $\left(\mathrm{m}^{2} \mathrm{KW}^{-1}\right)$.

Fricke has the lowest SSD (0.000229) followed by Maxwell (0.000297), Ju Wie (0.000314), Schuhmeister (0.001136876), and Militký (0.00171).

Figure 9 shows the effect of moisture content (\%) on the thermal resistance of P7 sock (acrylic $81.25 \%$, polyester $17.06 \%$, and elastene $1.69 \%$ ). All the models have a reasonable prediction of thermal resistance as evident in Figure 11. Lesser the SSD, better the prediction. Maxwell has the lowest SSD $(0.0000517)$ followed by Ju Wie (0.00134), Fricke (0.000135), Schuhmeister (0.00032638), and Militký (0.000744).

Figure 10 shows the model wise coefficient of correlation between theoretical and experimental thermal resistance in dry/wet states by all the models for all the sock samples irrespective of sock composition. Maxwell has the highest correlation $\left(R^{2}=0.8559\right)$ followed by Fricke $\left(R^{2}=0.8312\right)$, Ju Wie $\left(R^{2}=0.8224\right.$, Schuhmeister $\left(R^{2}=0.8079\right)$, and Militký $\left(R^{2}=0.873\right)$. 
Table 4. Thermal resistance at various moisture levels (predicted vs experimental)

\begin{tabular}{|c|c|c|c|c|c|c|c|}
\hline \multirow[b]{2}{*}{ Sock code } & \multirow{2}{*}{$\begin{array}{c}\text { Moisture } \\
\text { content (\%) }\end{array}$} & \multicolumn{5}{|c|}{ Thermal resistance $\left(\mathrm{m}^{2} \mathrm{KW}^{-1}\right)$} & \multirow[b]{2}{*}{ Experimental } \\
\hline & & $\begin{array}{l}\text { Fricke } \\
\text { modified }\end{array}$ & $\begin{array}{l}\text { Ju Wie } \\
\text { modified }\end{array}$ & $\begin{array}{l}\text { Maxwell } \\
\text { modified }\end{array}$ & $\begin{array}{l}\text { Schuhmeister } \\
\text { modified }\end{array}$ & $\begin{array}{c}\text { Militky } \\
\text { modified }\end{array}$ & \\
\hline \multirow{5}{*}{ P1 } & 10.10 & 0.029075 & 0.026768 & 0.0259 & 0.017867 & 0.014374 & 0.0256 \\
\hline & 20.61 & 0.027054 & 0.025002 & 0.0236 & 0.015748 & 0.012458 & 0.0204 \\
\hline & 44.03 & 0.02069 & 0.020234 & 0.0172 & 0.010955 & 0.008389 & 0.0105 \\
\hline & 61.17 & 0.01311 & 0.015747 & 0.0104 & 0.007288 & 0.005534 & 0.0082 \\
\hline & 67.02 & 0.009509 & 0.013955 & 0.0075 & 0.005909 & 0.004538 & 0.0071 \\
\hline \multirow{5}{*}{ P2 } & 6.62 & 0.025473 & 0.023683 & 0.0221 & 0.01491 & 0.011775 & 0.0275 \\
\hline & 20.22 & 0.022432 & 0.021359 & 0.0190 & 0.012422 & 0.009634 & 0.0208 \\
\hline & 43.83 & 0.015047 & 0.016653 & 0.0121 & 0.008206 & 0.006242 & 0.0101 \\
\hline & 57.88 & 0.008557 & 0.013343 & 0.0068 & 0.005574 & 0.004311 & 0.008 \\
\hline & 64.46 & 0.004649 & 0.011632 & 0.0038 & 0.003955 & 0.003246 & 0.0076 \\
\hline \multirow{5}{*}{ P3 } & 0.58 & 0.026292 & 0.024315 & 0.0236 & 0.017934 & 0.014817 & 0.0304 \\
\hline & 0.70 & 0.026276 & 0.0243 & 0.0236 & 0.017911 & 0.014795 & 0.0277 \\
\hline & 1.39 & 0.026183 & 0.024212 & 0.0235 & 0.01778 & 0.014667 & 0.0271 \\
\hline & 34.26 & 0.020171 & 0.019273 & 0.0171 & 0.011545 & 0.009006 & 0.016 \\
\hline & 49.55 & 0.015646 & 0.01628 & 0.0128 & 0.008636 & 0.006615 & 0.0154 \\
\hline \multirow{5}{*}{ P4 } & 2.57 & 0.030954 & 0.028764 & 0.0281 & 0.023101 & 0.019639 & 0.0346 \\
\hline & 6.03 & 0.030477 & 0.028291 & 0.0276 & 0.022303 & 0.018822 & 0.0339 \\
\hline & 19.67 & 0.028311 & 0.026266 & 0.0251 & 0.019125 & 0.015691 & 0.0232 \\
\hline & 36.99 & 0.024601 & 0.02319 & 0.0212 & 0.015009 & 0.011907 & 0.0223 \\
\hline & 52.27 & 0.019801 & 0.019791 & 0.0164 & 0.011276 & 0.008725 & 0.0183 \\
\hline \multirow{5}{*}{ P5 } & 0.00 & 0.028914 & 0.027095 & 0.0264 & 0.023489 & 0.020484 & 0.0231 \\
\hline & 0.72 & 0.028821 & 0.027001 & 0.0263 & 0.023319 & 0.020302 & 0.0225 \\
\hline & 21.45 & 0.025759 & 0.024122 & 0.0228 & 0.018425 & 0.015291 & 0.0221 \\
\hline & 53.34 & 0.017837 & 0.01824 & 0.0148 & 0.010739 & 0.008376 & 0.0127 \\
\hline & 66.20 & 0.012062 & 0.014911 & 0.0097 & 0.007466 & 0.005771 & 0.0107 \\
\hline \multirow{5}{*}{ P6 } & 4.24 & 0.038036 & 0.035071 & 0.0344 & 0.024769 & 0.020317 & 0.0488 \\
\hline & 11.46 & 0.036815 & 0.033891 & 0.0330 & 0.023166 & 0.018792 & 0.0408 \\
\hline & 17.99 & 0.035563 & 0.032729 & 0.0316 & 0.021677 & 0.017409 & 0.0353 \\
\hline & 43.62 & 0.028582 & 0.027029 & 0.0242 & 0.015439 & 0.011936 & 0.0202 \\
\hline & 54.13 & 0.024144 & 0.023973 & 0.0199 & 0.012662 & 0.009662 & 0.019 \\
\hline \multirow{5}{*}{ P7 } & 3.53 & 0.040875 & 0.038067 & 0.0366 & 0.029739 & 0.02492 & 0.0428 \\
\hline & 7.01 & 0.040085 & 0.037346 & 0.0357 & 0.028579 & 0.023773 & 0.0339 \\
\hline & 22.11 & 0.036104 & 0.03396 & 0.0313 & 0.023589 & 0.01904 & 0.0329 \\
\hline & 40.37 & 0.029509 & 0.029102 & 0.0247 & 0.01762 & 0.013786 & 0.0223 \\
\hline & 51.56 & 0.023884 & 0.025541 & 0.0195 & 0.013954 & 0.010773 & 0.0183 \\
\hline
\end{tabular}




\section{Conclusion}

By adopting the new approach of feeding wet polymer filling coefficient and thermal conductivity instead of dry polymers, different models can make a reasonable prediction of thermal resistance in wet states as well. All the models have a coefficient of determination $\left(R^{2}\right)>0.78$.

Polymer filling coefficient remains constant while water and air filling coefficients are changing with the variation of moisture which leads to change the thermal conductivity.

P3, P4, and P5 socks samples have resumed their dry (laboratory conditions) $R_{c t}$ after $6 \mathrm{~h}$ of conditioning. P1, P6, and P7 could not resume their insulation even after $8 \mathrm{~h}$ of conditioning.

This study was conducted after successive periods of intervals to monitor the evaporation rate as well. So that many moisture contents (\%) point missed in the graphs for some samples. The next study could be planned to test controlled moisture [32].

\section{Acknowledgment}

This work was funded by the Technical University of Liberec, Czech Republic by SGS-2019 under project number 21314.

\section{References}

[1] Slater, K. (1986). Discussion paper the assessment of comfort. The Journal of the Textile Institute, 77(3), 157171.

[2] Adler, M. M., Walsh, W. K. (1984). Mechanisms of transient moisture transport between fabrics. Textile Research Journal, 54(5), 334-343.

[3] Woodcock, A. H. (1962). Moisture transfer in textile systems, Part I. itleTextile Research Journal, 32(8),628633.

[4] Gagge, A. P., Gonzalez, R. R. (1974). Physiological and physical factors associated with warm discomfort in sedentary man. entalEnvironmental Research, 7(2), 230242.

[5] Plante, A. M., Holcombe, B. V., Stephens, L. G. (1995). Fiber hygroscopicity and perceptions of dampness part I: Subjective trials. Textile Research Journal, 65(5), 2932985.

[6] Wong, A. S. W., Li, Y. (1999). Psychological requirement of professional athlete on active sportswear. In: The 5th Asian Textile Conference, Kyoto, Japan, 1999.

[7] Havenith, G., Holmér, I., Meinander, H., DenHartog, E., Richards, M., et al. (2006). Assessment of thermal properties of protective clothing and their use. EU Final Report.

[8] Lotens, W. (1993). Ph.D. Dissertation. TU Delft, Delft University of Technology.

[9] Bogusławska-Bączek, M., Hes, L. (2013). Effective water vapour permeability of wet wool fabric and blended fabrics. Fibres \&Textiles in Eastern Europe, 21(97), 67-71.
[10] Oğlakcioğlu, N., Marmarali, A. (2010). Thermal comfort properties of cotton knitted fabrics in dry and wet states. Tekstil ve Konfeksiyon, 20(3), 213-217.

[11] Chen, Y. S., Fan, J., Zhang, W. (2003). Clothing thermal insulation during sweating. Textile Research Journal, 73(2), 152-157.

[12] Kuklane, K., Holmér, I. (1998). Effect of sweating on insulation of footwear. International Journal of Occupational Safety and Ergonomics, 4(2), 123-136.

[13] Kuklane, K., Holmer, I., Giesbrecht, G. (1999). Change of footwear insulation at various sweating rates. Applied Human Science, 18(5), 161-168.

[14] Richards, M. G. M., Rossi, R., Meinander, H., Broede, P., Candas, V., et al. (2008). Dry and wet heat transfer through clothing dependent on the clothing properties under cold conditions. International Journal of Occupational Safety Ergonomics, 14(1), 69-76.

[15] Kanat, Z. E., Özdil, N. (2018). Application of artificial neural network (ANN) for the prediction of thermal resistance of knitted fabrics at different moisture content. The Journal of the Textile Institute, 109(9), 1247-1253.

[16] Matusiak, M. (2013). Modelling the thermal resistance of woven fabrics. The Journal of the Textile Institute, 104(4), 426-437.

[17] Qian, X., Fan, J. (2006). Prediction of clothing thermal insulation and moisture vapour resistance of the clothed body walking in wind. Annals of Occupational Hygiene, 50(8), 833-842.

[18] Mangat, M. M., Hes, L. (2014). Thermal resistance of denim fabric under dynamic moist conditions and its investigational confirmation. Fibres \& Textiles in Eastern Europe, 22(6), 101-105.

[19] Mangat, M. M., Hes, L., Bajzík, V. (2015). Thermal resistance models of selected fabrics in wet state and their experimental verification. Textile Research Journal, 85(2), 200-210.

[20] Hollies, R. S., Bogaty, H. (1965). Some thermal properties of fabrics: part II: the influence of water content. Textile Research Journal, 35(2), 187-190.

[21] Naka, S., Kamata, Y. (1977). Thermal conductivity of wet fabrics. Journal of the Textile Machinery Society of Japan, 23(4), 114-119.

[22] Wei, J., Xu, S., Liu, H., Zheng, L., Qian, Y. (2015). Simplified model for predicting fabric thermal resistance according to its microstructural parameters. Fibres \& Textiles in Eastern Europe, 23(4), 57-60.

[23] Hes, L., Dolezal, I. (1989). New method and equipment for measuring thermal properties of textiles. Sen'i Kikai Gakkaishi (Journal Text. Mach. Soc. Japan), 42(8), T124-T128.

[24] Fricke, H. (1924). A mathematical treatment of the electric conductivity and capacity of disperse systems I. The electric conductivity of a suspension of homogeneous spheroids. Physical Review, 24(5), 575.

[25] Maxwell, J. C. (1954). A treatise on electricity and magnetism.

[26] Eucken, A. (1940). Allgemeine gesetzmäßigkeiten für das wärmeleitvermögen verschiedener stoffarten und aggregatzustände. Forschung auf dem Gebiet des Ingenieurwesens A, 11(1), 6-20. 
[27] Carson, J. K. (2002). Prediction of the thermal conductivity of porous foods: A thesis submitted in partial fulfilment of the requirements for the degree of Doctor of Philosophy in Food Engineering, Massey University, Palmerston North, New Zealand, 2002. Massey University.

[28] Schuhmeister, J. (1877). Ber. K. Akad. Wien (Math-Naturw. Klasse), vol. 76, p. 283.

[29] Militký, J., Becker, C. (2011). Selected topics of textile and material science. Select Topics of Textile and Material Science, p. 404.
[30] Ullmann, F. (2008). Ullmann's fibers., vol. 1. Wiley-VCH Verlag (Weinheim).

[31] Lowther, J., Keller, G., Warwick, B. (2006). Statistics for management and economics, 48(9). Cengage Learning.

[32] Haghi, A. K. (2005). Experimental survey on heat and moisture transport through fabrics. International Journal of Applied Mechanics and Engineering, 10(2), 217-226.

[33] Dias, T., Delkumburewatte, G. B. (2007). The influence of moisture content on the thermal conductivity of a knitted structure. Measurement Science and Technology, 18(5), 1304. 